\title{
Museum of the Underway Artists - Metanarratives on Networks
}

\section{SIGRADI2018 TECHNOPOLITICAS \\ xxii congresso da sociedade iberoamericana de gráfica digital 22th conference of the iberoamerican society of digital graphics 07|08|09|novembro|2018 iau usp | são carlos | sp br}

\author{
Cássia Hosni \\ Universidade de São Paulo | Brazil | cassiahosni@usp.br \\ Didiana Prata \\ Universidade de São Paulo | Brazil | didianaprata@usp.br \\ Erica Ferrari \\ Universidade de São Paulo | Brazil | ericaferrari@usp.com \\ Nathalia Lavigne \\ Universidade de São Paulo | Brazil | nlavigne@usp.br
}

\begin{abstract}
This article draws attention to an experience of workshop Masp.Etc.Br carried out by the Research Group Aesthetics of Memory of the 21st Century at the São Paulo Museum of Art (MASP), in which an aesthetic mapping of Paulista Avenue was done to discuss collaborative processes of image production organized through hashtags. The material gathered was an ample set of images posted on Instagram. After two collaborative edition processes, a final version was projected as a video at the free span of the Museum. These experiences bring attention to the aesthetics of the database and narratives in social networks.
\end{abstract}

Keywords: São Paulo Museum of Art; MASP; Paulista Avenue; Public space; Database Aesthetics.

\section{INTRODUÇÃO}

Pensar o museu como um espaço de constantes disputas narrativas, propondo um diálogo com o território onde está localizado e com o universo colaborativo das redes sociais foi uma das ideias iniciais do projeto Masp.Etc.Br, organizado pelo Grupo de Pesquisa Estéticas da Memória no Século 21 - CNPq. Partiu-se das investigações individuais de cada membro acerca do novo status da imagem, das narrativas visuais colaborativas das redes e de metodologias de visualização em banco de dados. A proposta constituiu-se originalmente a partir de uma oficina realizada em maio de 2017 no Museu de Arte de São Paulo (MASP), como parte da programação da exposição 'Avenida Paulista'. Desenvolveu-se um laboratório para o mapeamento estético da própria Avenida, mesclando registros fotográficos e videográficos produzidos com câmeras celulares por um grupo de 35 pessoas durante dois dias. Para tanto, partimos para uma deriva urbana com o objetivo de apreender e captar a ampla varredura da produção estética da Paulista, documentando a diversidade de usos e acontecimentos efêmeros ao redor da Avenida: performers, ambulantes, artesãos, manifestantes, monumentos, moradores de rua, câmeras de vigilância etc. Organizados por meio de uma hashtag principal (\#maspetcbr), o primeiro corpo de imagens captadas foi publicado no Instagram como chamada coletiva aberta. Em um segundo momento, criaram-se outras hashtags secundárias - cocriadas com os participantes - que contribuíram para o processo de organização e visualização do material. No caso do Instagram, as hashtags seriam uma boa maneira de verificar as meta-narrativas, organizadas a partir de diferentes tipos de imagens compartilhadas. A partir desse conjunto de registros, foi realizada uma seleção pelos integrantes da oficina, a edição em blocos e a compilação final. A montagem do material buscou interferir o mínimo possível nas imagens captadas, buscando que a criação de sentidos ocorresse de modo mais livre possível. No último dia de atividade, o resultado foi projetado no vão livre do Museu, aqui entendido como um lugar de confrontos e encontros da nossa história recente que vai muito além da instituição. Em uma situação de cinema deitado, quem passasse naquele momento pela Avenida era convidado a assistir à projeção que era realizada na laje do Museu. A intenção foi promover, através dos registros de caminhada pelo espaço interno e ao redor do museu, uma reflexão sobre a apreensão estética cotidiana por meio de dispositivos móveis e sua relação crítica com a arte e o espaço urbano.

\section{Metodologia}

A oficina foi configurada com a duração de três dias. No primeiro, houve uma discussão introdutória sobre a deriva urbana, mapeamento e formas de registro nos dispositivos móveis. A seguir, propomos a produção de um banco de dados composto por imagens audiovisuais do MASP e da Avenida Paulista, produzidos com os dispositivos móveis dos participantes. Também foram 
desenvolvidos acrônimos que dialogavam com a sigla MASP, acoplando uma diversidade de significações para cada uma das iniciais da sigla. Um acrônimo é uma abreviatura feita pela junção de partes de outras palavras que têm pronúncia silábica. No universo da cultura digital, os acrônimos são usados para formar palavras que ainda não existem. O acrônimo MASP é um Museu-mundo da Avenida Paulista e de tudo aquilo que a avenida é para além de seus limites geográficos. Dentre os acrônimos formados destacam-se: Museu dos Artistas Sob Passagem, Música na Avenida com Segurança e Privacidade, Município Aberto Semi Privado, Manos Arte Sem Plágio, Museu Artigos Subterrâneo Pixador, Museu da Acrópole Sem Pessoas, Mapeamento Artístico Social Popular, Museu de Arte e Seus Parceiros, Museu de Áudio da Sua Playlist, Museu dos Artistas Sem Público, Muita Arte Super Pop, Museu do Amanhã Sem Presente. O desenvolvimento de acrônimos se tornou uma atividade ilimitada e replicável por qualquer pessoa, um exercício de deslocamento de significados do nome do Museu. E uma provocação para o imaginário do participante da oficina.

No primeiro dia propôs-se uma deriva para a apreensão estética da paisagem urbana pelo caminhante, captura de imagens e a produção de material representativo dessa experiência. A ideia era que o material fosse produzido levando-se em conta a utilização de estratégias objetivas de tagueamento no aplicativo Instagram. Esse processo partiu do levantamento das possíveis manifestações estéticas encontradas no ambiente cotidiano do local e de seus frequentadores, tendo como pano de fundo a produção contemporânea de imagens em meios digitais, permeadas pelos conceitos de apropriação e edição, categorização e taxonomia, fluxo e circulação e inseridas no contexto da linguagem e criação artística.

No segundo momento do projeto, foi realizada a categorização e edição do material coletado com o objetivo de construção de uma possível narrativa polissêmica abarcando os diversos usos, características e relações que se estabelecem dentro do Museu, do Museu com seu entorno e da própria Avenida Paulista. Algumas hashtags (\#) temáticas foram escolhidas para ajudar no processo de elaboração do material audiovisual final a partir das postagens no Instagram. Foram elas: \#artepublica, \#artistaspaulista, \#manifestacaopaulista, \#maspmuseu, \#paulistaaberta, \#vaolivre. Essa estratégia possibilitou a organização das imagens produzidas pelos integrantes em eixos narrativos complementares, representativos da diversidade das questões políticas e artísticas inerentes à Avenida Paulista e ao MASP, além da própria atividade do projeto. A metodologia de visualização de dados a partir de \# (hashtag) + palavrachave é utilizada cada vez mais em trabalhos artísticos, como "On Broadway", de autoria de Lev Manovich, e "Cinema sem volta", de Giselle Beiguelman. Nessas obras, fica explícito como registros fragmentados e desconectados, quando agrupados sob uma mesma hashtag, podem transferir à imagem móvel novas funções relacionadas à crítica e à curadoria, em um jogo narrativo inédito. Os registros então foram baixados do Instagram, organizados através das hashtags e por meio de um software. As fotografias e vídeos foram acopladas respeitando como parâmetro a montagem por afinidades temáticas.
Por fim, o terceiro momento do projeto configurou-se como uma apresentação do material audiovisual constituído pelos registros capturados pelos integrantes, os acrônimos produzidos e outras inserções de áudio. Esse vídeo final foi projetado no vão livre do Museu, utilizando o seu teto como superfície, junto a caixas de som. Os integrantes, os membros do Grupo de Pesquisa, os frequentadores, a equipe do MASP, os moradores sem teto do local e os transeuntes da Avenida foram convidados a assistir à projeção acomodados em cadeiras e colchonetes.

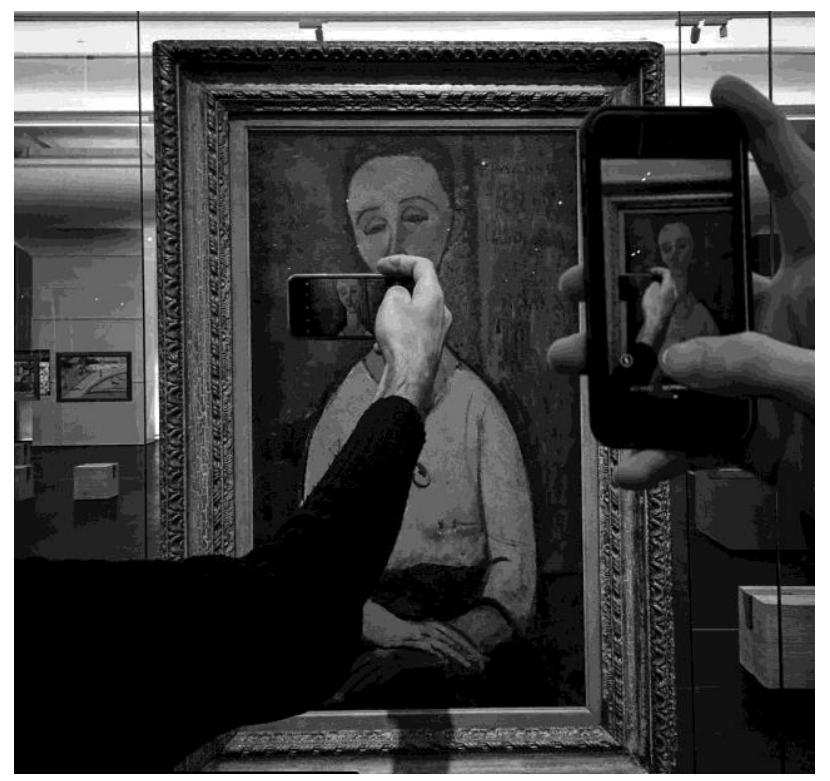

Figura 1: público fotografando obra no MASP. Fonte: autores.

\section{REsultados}

Propomos refletir sobre a construção de narrativas colaborativas nas redes por meio de uma oficina teóricoprática. A partir dessa experiência, verificamos modos de produzir linguagem como uma criação multiautoral, coletiva e polissêmica. Após o primeiro dia da oficina, foram coletados mais de dois mil registros captados pelos integrantes da oficina. No segundo dia, essa imageria foi organizada e editada pelos participantes a partir das hashtags. Já os trechos fílmicos foram compilados pelos acrônimos selecionados. O audiovisual final foi produzido a partir de todo esse material e buscou-se a mínima manipulação diante do material coletado. O local de projeção do filme, no vão livre do MASP, também constituiu uma ação performática e buscava provocar um diálogo com as mensagens e os conteúdos das narrativas e o entorno urbano. O material, projetado horizontalmente na laje, permitia uma experiência cinemática a partir de outros pontos de vista. No embate com a cidade e com os territórios informacionais, interrogamos quais narrativas podem ser construídas a partir dos processos de mapeamento orientado e das filtragens de hashtags. Esse conjunto reverberou a experiência da vivência no espaço público e no Museu, refletindo as questões inerentes aos diversos modos de fruição da Avenida Paulista e do MASP. A montagem deste material, produzido coletivamente, demonstrou a potencialidade das construções narrativas colaborativas, um dos objetivos propostos para o projeto. Usando a arquitetura do próprio Museu como superfície da projeção, introduzimos mais uma camada de informação 
relacionada ao espaço mesclando as imagens digitais à paisagem urbana.

Além da projeção final, um segundo resultado a ser apontado é a permanência e continuidade do projeto por meio da hashtag \#maspetcbr. Um recorte da interface do Instagram em uma busca por essa palavra-chave revela aproximações interessantes para pensar nas confluências entre o espaço do Museu e da Avenida, um dos locais mais vivos da cidade e palco de diversos tipos de manifestações artísticas e políticas. O vão livre, especialmente, ponto de inúmeras manifestações recentes, foi casualmente ocupado no dia da oficina pela Marcha da Maconha, que acabou ganhando relevância na cobertura e destaque na miscelânea de imagens do \#maspetcbr.
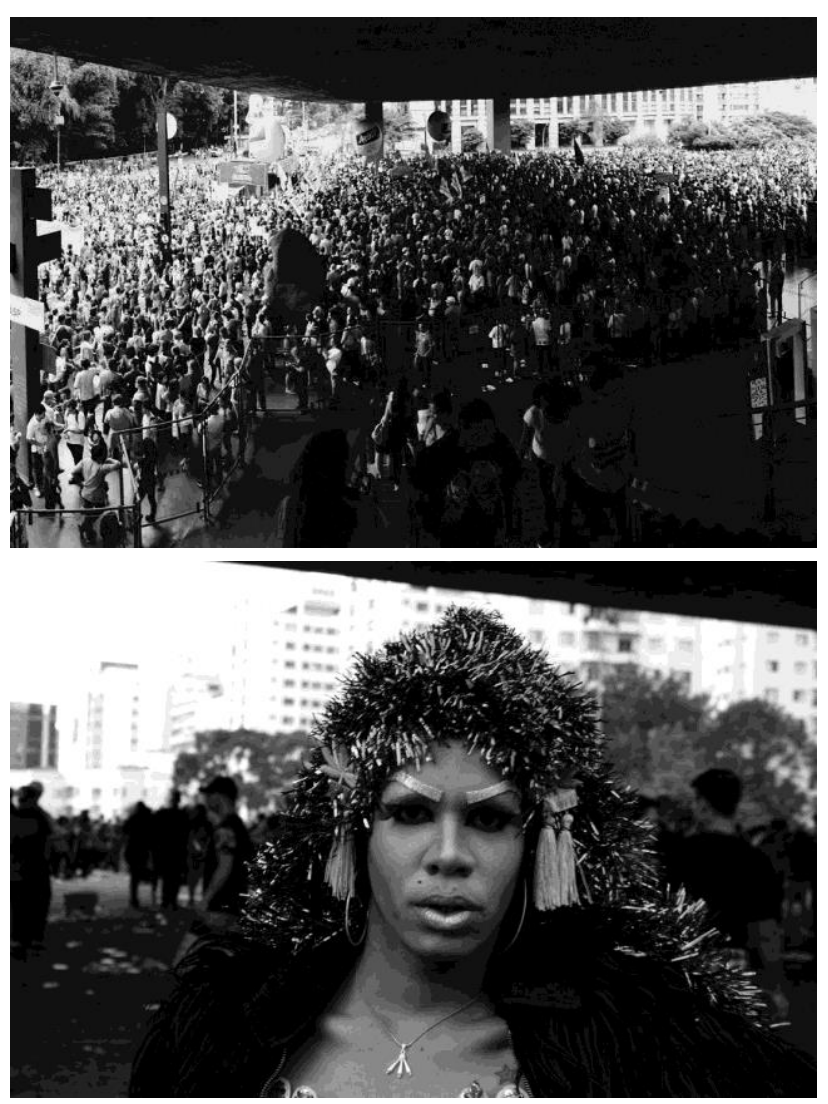

Figura 2 e 3: registros de manifestações no vão livre do MASP. Fonte: autores.

\section{DIscussão}

A estética do banco de dados, visualizada nesse trabalho pelas narrativas colaborativas produzidas pelos participantes da oficina, representam camadas narrativas da cidade contemporânea. Esses registros, produzidos, mediados e publicados por dispositivos móveis, mostram muito além da estetização do cotidiano - e do cidadão munido de uma câmera celular. Eles revelam, como diz Jacques Rancière, a partilha do sensível do "qualquer um", do artista anônimo, do cidadão participante do jogo estético das redes e de novos modos de viver e apreender a paisagem urbana. As tensões territoriais e as disputas políticas e artísticas são representadas por esses registros. A intenção do projeto aqui exposto foi transfigurar esse material para uma reflexão por meio da linguagem poética, contando com a experiência dos próprios integrantes durante a oficina e a elaboração de uma peça audiovisual coletiva ao final, apresentada no espaço público.

Rancière afirma que é justamente no terreno estético que se trava hoje a discussão política, a generalização do espetáculo e a multiplicação dos discursos. Estamos constantemente dando visibilidade às relações sociais, culturais e políticas e, portanto, produzindo no campo da estética nossa manifestação discursiva. O autor propõe um novo regime das artes no qual "a revolução estética é antes de tudo a glória do qualquer um" (Rancière, 2005, p. 48). Esse princípio confere visibilidade ao anônimo, que produz arte e confere beleza a outros modos de representação, destituídos de sistemas e hierarquias das artes visuais. Para o autor, dar visibilidade é uma operação política. A experiência de novas formas de representação estética de imagens digitais nas redes se dá de diferentes formas. Vemos a realidade cotidiana autenticada por imagens que seguem diversos estilos, de acordo com o repertório de cada um. São imagens produzidas e utilizadas, na maioria das vezes, como emissores de experiências hedonistas ou de manifestações poéticas de diferentes naturezas.

\section{Museu de Avenida Souvenirs Periferia}

\section{Município Artístico da Social Paliativas}

Figura 4: acrônimos MASP. Fonte: autores. 
Ao utilizarmos as hashtags e desdobrá-las em diversas formas de organização e apresentação, propõem-se novas narrativas através do projeto. Cada imagem conecta-se a outras, dando visibilidade a uma narração coletiva. Com o uso de tagueamentos, a estética dessa imagem passa a ter uma natureza dupla. Ela faz parte de uma história singular, contextualizada por seu autor, e, simultaneamente, pertence à história colaborativa, suscetível à deslocamentos, novos agrupamentos e permeável à outras camadas narrativas.

Essa meta-narrativa reflete a ideia de um museu imaginário desenvolvida pelo autor francês André Malraux, que descreve os processos de deslocamento dos objetos em museus como o resultado de um "diálogo de ressurreições", no qual os discursos sobre essas obras vão sendo construídos pelos imaginários de cada época e sobrepondo-se uns aos outros (Malraux, 1965). Esse evento, visto em um recorte específico, reforça o potencial da Avenida Paulista como espaço aglutinador de diferentes vozes e conflitos, sendo mais um índice a ser incorporado nos discursos institucionais do Museu no momento atual. Assim como a lógica de um museu sem fim (etc.br) sugere a ideia de um processo contínuo, a edição por meio de hashtags colaborativa também acontece como um processo permanente. Embora haja um critério seletivo - imagens feitas naquele perímetro da Avenida ou dentro do museu - não há outro limite possível, nem de quantidade nem de como cada um entende suas representações. A participação colaborativa, nesse caso, se dá pelo excesso e a miscelânea, ampliando ao máximo a leitura do que pode ser entendido pela noção de museu.
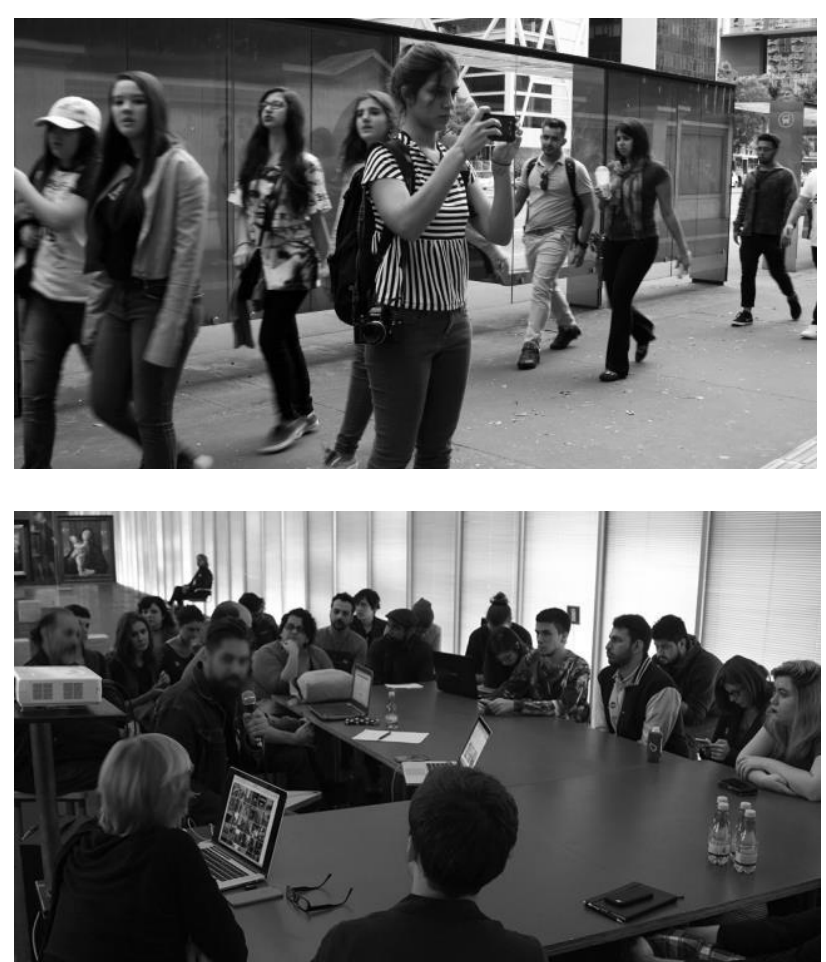

Figura 5 e 6: captura e edição durante oficina. Fonte: autores.

Como aponta a teórica e curadora Christiane Paul, elementos da narrativa tradicional aparecem em diversos projetos criados a partir de bancos de dados, mas na forma de uma "meta-narrativa", em que a linguagem de um sistema determina outras possibilidades de organizar as informações (2006).

Os dados e as formas de tagueamento funcionam como a nova "legenda" das imagens informacionais. No projeto, a tag utilizada \#maspetcbr permite a visualização de todas os registros produzidos e postados durante a oficina. Há um deslocamento temporal e espacial no contexto de leitura dessas imagens e vídeos quando são agrupados coletivamente. A subjetividade da autoria, a composição e os rigores de composição formal, tonal, iluminação e contexto ficam em um segundo plano. O que se vê é uma grande "frase-imagem", uma sequência de frames heterogêneos que, lado a lado, passam a adquirir um novo significado.

O conceito da "frase-imagem", de Rancière (2011) também nos ajuda a fazer uma leitura mais cinemática desses fragmentos temáticos, na medida em que a montagem sequencial dos registros coletados pelo algoritmo pode ser manipulada. A hashtag e 0 deslocamento da imagem/vídeo em um contexto de montagem e reprodução técnica de fato se assemelha a procedimentos do cinema e do pós-cinema, nos quais a imagem digital, a fotografia, o vídeo e a imagem generativa são consideradas matérias-primas para a interface fílmica. De fato, a sequência de visualização das imagens no feed e na página do aplicativo mostra que o uso de hashtags (\#) é apenas uma primeira etapa da estratégia de edição desse trabalho de estética de banco de dados. A segunda e tão mais importante está o olho do editor ou editores, que capturaram esses registros, deslocaram suas sequências de postagens e constroem montagens, strips ou fotogramas sobre os temas enunciados. Para Victoria Vesna, a estética do projeto com imagens informacionais depende da manipulação do artista e de sua prática em lidar com dados, de como ele navega pelos "backbones" (rede de transporte de dados) das redes e consegue vislumbrar informações com uma vocação estética para seu projeto. Como a informação é organizada e o que deve ser publicado de forma estética depende do artista-editor (Vesna, 2007).

O viés cinemático dessas composições com registros heterogêneos é bastante relevante para entender as novas potencialidades do design de narrativas. A imagem informacional é híbrida, metamórfica e passa a assumir novas funções quando deslocada e inserida em montagens digitais, aqui tendo como exemplo o próprio projeto desenvolvido como um experimento audiovisual realizado coletivamente pelos integrantes da oficina e pelo Grupo de Pesquisa. O registro digital é na sua essência móvel. Ao elucidar conceitos relacionados à cultura digital, Lev Manovich traça um interessante paralelo com teorias aplicadas ao cinema e traz referências icônicas como o filme "Um homem com uma câmera" (Man with a Movie Camera), de Dziga Vertov (1929), para ilustrar seu vocabulário sobre as novas mídias. A multiplicidade de ações e procedimentos práticos e estéticos realizados no cinema de Vertov serve como exemplo para conceitos como composição digital, montagem, signos móveis, hierarquia de camadas dos objetos de mídia, interface e conteúdo, sistemas operacionais, linguagem, programação e novas estéticas e procedimentos (2001). Entre eles, processos de copy \& paste, de repetição e loop são usados nos filmes e 
explorados por Vertov, preconizando a prática do GIF, formato largamente utilizado hoje em dia na web.

O projeto aqui explicitado empregou o GIF nas peças de comunicação, incorporando-o como linguagem comunicacional. Esses recursos de fato caracterizam os novos formatos narrativos da era das redes. O conceito do loop cinemático se estende ao GIF e à sequência das imagens "aglutinadas" sobre o mesmo algoritmo temático, no caso aqui da mesma hashtag do Instagram. A sequência de registros montada em uma organização cinética ou visualizadas por meio da programação de dados nos aplicativos alteram o fluxo linear das narrativas.

Segundo Manovich, decodificar o mundo por meio de imagens manipuladas é relevante para o estudo das novas mídias: "As narrativas das novas mídias e as novas interfaces podem explorar novas possibilidades de composição e estética oferecidas pelos bancos de dados dos computadores" (Manovich, 2001, p. 10). Analisando as estratégias realizadas na composição da peça audiovisual final do projeto aqui exposto fica evidente como o "artista anônimo", autor das imagens apropriadas do Instagram, contribui no jogo e na construção de uma narrativa coletiva urbana. Verifica-se como o processo de agrupar códigos html e composições realizados por softwares de edição de vídeo - utilizados com um propósito definido e em torno de um argumento crítico podem gerar narrativas visuais singulares. Nesse aspecto, no projeto elaborado atentou-se para uma nova apresentação diante do conteúdo de registros que circulam no Instagram. Ao invés de mostrar frames únicos, em que se ressalta a autoria, foram apresentados registros múltiplos sem a identificação dos nomes. A discussão mediada pelo Grupo de Pesquisa Estéticas da Memória no Século 21 permitiu um exercício de ressignificação do espaço do Museu e da Avenida Paulista por meio da experiência empreendida e do conteúdo audiovisual dos integrantes.

Além da captura e das manifestações imagéticas, a projeção da peça audiovisual final transpôs para o espaço intersticial do vão do MASP uma terceira etapa do projeto, onde o teto do Museu se tornou tela, circundada pelo espaço urbano. A arquitetura do prédio é um marco do século 20 e o vão livre funciona como uma praça a ser ocupada pela população, abrigando diversas manifestações culturais e políticas. O vão foi instituído por lei, assegurando sua vocação de espaço público aberto e de mirante que remonta à sua configuração original. $\mathrm{Na}$ sua empena, o Belvedere Trianon tomou forma como ponto de consolidação da Avenida Paulista em lugar nobre, espaço de encontro e lazer da elite, configurandose como mirante aberto para observação do Córrego Saracura e das montanhas ao redor. Mesmo com a construção do edifício do MASP em seu lugar, o espaço manteve a praça livre, ponto de referência da produção estética da Paulista, de seus performers, ambulantes, artesãos, manifestantes, monumentos, moradores de rua, câmeras de vigilância, etc. A projeção final no vão do MASP reforça a vocação de espaço público, onde deu-se visibilidade a novas formas de produção estética, por meio da ocupação audiovisual temporária realizado pelo projeto. No Instagram, a narrativa visual do \#masp.etc.br representa a amplitude e a diversidade do uso desse espaço eventual.
Assim, nota-se que o argumento da narrativa se apresenta como o elemento central para organizar a edição de imagens em diferentes técnicas. Como a quantidade de recursos e a manipulação de softwares e aplicativos é infinita, cabe aos designers e artistas saberem usar e misturar dados em novos formatos em prol de um discurso ou de uma mensagem. O desafio é justamente manter o fio narrativo em torno de uma comunicação visual, na qual a composição, a montagem e o encadeamento seja essencial para garantir a compreensão do argumento. Como propositores, o Grupo de Pesquisa Estéticas da Memória no Século 21 lançou os dados, oferecendo aos integrantes da oficina uma metodologia diante tantas outras possíveis para a criação coletiva. O projeto Masp.Etc.Br foi um diálogo entre o espaço da Avenida Paulista, a arquitetura, a instituição museológica, seus usuários e espectadores, tendo sempre em mente as possíveis aberturas para a imprevisibilidade da produção estética.

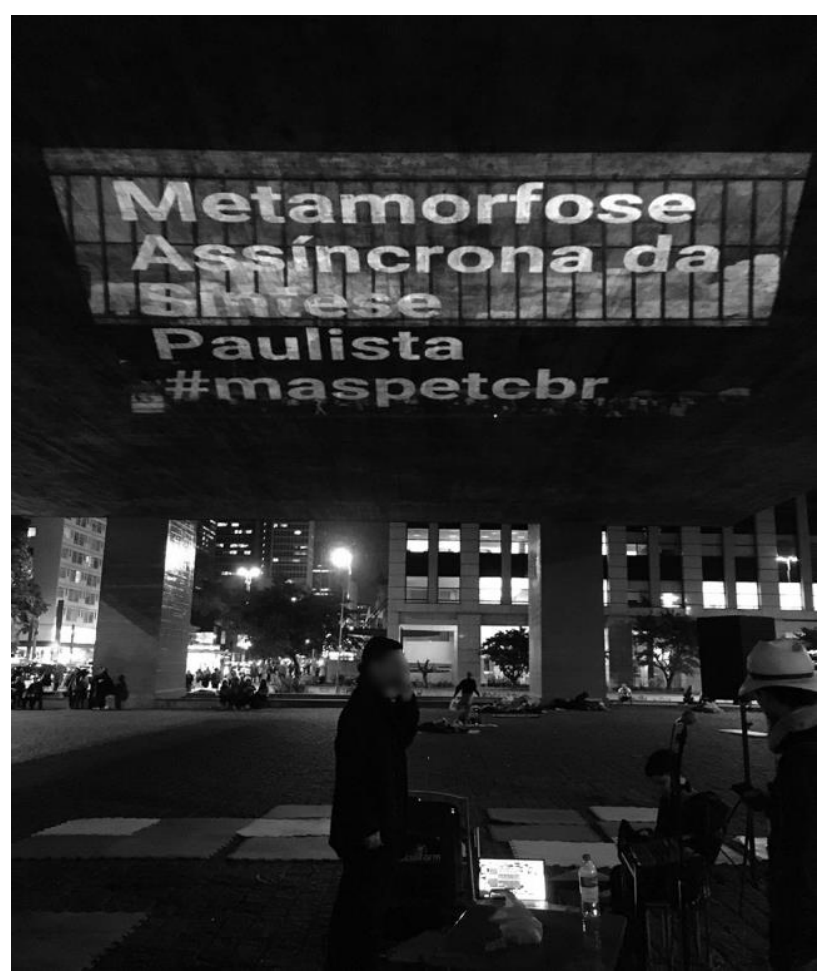

5

Figura 7: projeção no teto do vão livre do MASP. Fonte: autores.

\section{AGRADECIMENTOS}

A realização da oficina Masp.Etc. $\mathrm{Br}$ foi realizada pelo Grupo de Pesquisa Estéticas da Memória no Século 21 CNPq, composto por Andre Deak, Artur Cordeiro, Cássia Hosni, Didiana Prata, Erica Ferrari, Giovanna Graziosi Casimiro, Lucas Bambozzi, Nathalia Lavigne, Rodrigo Terra, Renato Almeida Prado e coordenação de Giselle Beiguelman. Agradecemos ao MASP, em especial ao Leonardo Matsuhei e ao Pedro Andrada pelo convite.

\section{REFERÊNCIAS}

Beiguelman, G., \& La Ferla. J. (2011). Nomadismos tecnológicos. São Paulo: Senac.

Castells, M. (2011). Museus na era da informação: conectores culturais de tempo e espaço. Revista Musas 5, 8-21. Retrieved from http://www.museus.gov.br/wpcontent/uploads/2015/01/Revista-Musas-5.pdf. 
Estéticas da memória no século 21. (2017, mar). Masp.Etc.br [Video Archive]. Retrieved from https://www.youtube.com/watch?v=De6DaSJEqq8

Manovich, L.(2001). The Language of New Media.Massachusetts: MIT Press.

Manovich, L. (2016). Designing and Living Instagram Photography: Themes, Feeds, Sequences, Branding, Faces, Bodies. Retrieved from http://manovich.net/index.php/projects/designing-and-livinginstagram-photography.

Manovich, L. (2017). Instagram and Contemporary Image. Retrieved from http://manovich.net/index.php/projects/instagram-andcontemporary-image

Masp.Etc.Br. (2017). Retrieved from http://outrosurbanismos.fau.usp.br/maspetcbr.Maulraux, A. (1965). O Museu Imaginário. Lisboa: Edições 70.

Paul, C. (2006). Digital Art/Public Art: Governance and Agency in the Networked Commons. First Monday, 0. doi: https://doi.org/10.5210/fm.v0i0.1616
Paul, C. (2007). The Database as System and Cultural Form: Anatomies of Cultural Narratives..In Vesna, V. (Ed), Database Aesthetics Art in the Age of Information Overflow. (p. 94-108). London: University of Minnesota Press.

Prata, D. (2016). Imageria e poéticas de representação da paisagem urbana nas redes. (Master's thesis).Faculdade de Arquitetura e Urbanismo da Universidade de São Paulo, São Paulo

Rancière, J. (2005). A partilha do sensível: estética e política. São Paulo: Editora 34.

Rancière, J. (2013). O destino das imagens. Rio de Janeiro: Contraponto.

Saad Corrêa, E.\& Bertocchi, D. (2012). O Algoritmo Curador: O papel do comunicador num cenário de curadoria algorítmica de informação. Retrieved from http://bibliodigital.unijui.edu.br:8080/xmlui/handle/123456789/ 2852.

Vesna, V. (Ed.). (2007). Database Aesthetics: Art in the Age of Information Overflow. University of Minnesota Press. 